\title{
National observational study to evaluate the Cleanyourhands campaign (NOSEC) in England and Wales 2004-8: a prospective ecological interrupted time series
}

\author{
S Stone ${ }^{1,2^{*}}$, NOSEC group ${ }^{1}$ \\ From International Conference on Prevention \& Infection Control (ICPIC 2011) \\ Geneva, Switzerland. 29 June - 2 July 2011
}

\section{Introduction / objectives}

WHO SAVE LIVES initiative offers nations a multimodal hand-hygiene intervention. England \& Wales rolled out similar intervention, the Cleanyourhands campaign (CYHC) (bedside alcohol hand-rub (AHR), posters, audit \& patient empowerment) to all 187 acute hospitals. We report results of independent study evaluating its national effectiveness \& sustainability.

\section{Methods}

6 questionnaires (5 voluntary, last mandatory) assessed CYHC implementation \& sustainability every 6 months. Quarterly data on MRSAB, MSSAB \& CDI, procurement soap \& AHR, hospital type \& bed occupancy collected for each hospital with data on other national infection control interventions Mixed effects Poisson regression model assessed associations between procurement \& HCAI rates, testing for hospital heterogeneity.

\section{Results}

Questionnaire response rates fell from 134 (71\%) at 6 months to $82(44 \%)$ at 30 months, rising to $167(90 \%)$ for final mandatory one. No evidence attritional/ selection bias. Widespread early implementation bedside AHR \& posters. At 36 months, 90\% respondents reported CYHC a top hospital priority, with implementation of AHR, posters \& audit reported by $96 \%, 97 \%$ and $91 \%$ respectively.

Combined soap \& AHR procurement rose from 22 to $60 \mathrm{mls} /$ bed day. MRSAB rate fell from 1.88 to 0.91

'Universirt College London, London, UK

Full list of author information is available at the end of the article cases/10000 beddays \& CDI from 16.75 to 9.49 . MSSAB did not fall.

Each extra ml/bed-day of AHR associated with 1.3\% reduction MRSAB: IRR $0.987(0.983,0.991) \mathrm{p}<.0001)$. Each extra ml soapÂ associated with $0.33 \%$ reduction CDI (IRR 0.997 [0.995,0.998] $\mathrm{p}<0.0001)$. Associations remained after adjusting for other variables significantly associated with reductions MRSAB \& CDI: publication of Health Act \& Department of Health Improvement Team visits.

\section{Conclusion}

The CYHC appears to have been widely implemented \& sustained. Strong associations found between procurement AHR/soap \& reductions in MRSAB \& CDI, that remained after adjustment for other variables \& interventions. Campaign's central funding \& co-ordination and high profile political drive may affect its generalisability but may provide model for other countries to adopt to implement WHO SAVE LIVES initiative.

\section{Disclosure of interest}

S. Stone Grant/Research support from GOJO.

\section{Author details}

${ }^{1}$ Universirt College London, London, UK. ${ }^{2}$ Hand hygiene Liaison Group, London, UK.

Published: 29 June 2011

doi:10.1186/1753-6561-5-S6-P117

Cite this article as: Stone and : National observational study to evaluate the Cleanyourhands campaign (NOSEC) in England and Wales 2004-8: a prospective ecological interrupted time series. BMC Proceedings 20115 (Suppl 6):P117.

(c) 2011 Stone and NOSEC group; licensee BioMed Central Ltd. This is an open access article distributed under the terms of the Creative 